\title{
Rings, Chains and Helicates: Dependence of Metallosupramolecular Topology on Positional Substitution within Silver(I) Complexes of Six Isomeric Bis(2-pyridyloxy)naphthalenes
}

\author{
Brendan J. O'Keefe ${ }^{a}$ and Peter J. Steel ${ }^{* a}$ \\ ${ }_{5}$ Receipt/Acceptance Data [DO NOT ALTER/DELETE THIS TEXT] \\ Publication data [DO NOT ALTER/DELETE THIS TEXT] \\ DOI: 10.1039/b000000x [DO NOT ALTER/DELETE THIS TEXT]
}

Silver(I) nitrate complexes of six isomeric bis(2-pyridyloxy)naphthalenes, differing only in the substitution pattern within the central naphthalene unit, have been shown to have an unexpected 10 assortment of supramolecular architectures, including dimetallocyclophanes, linear coordination polymers and a single-stranded helicate.

\section{Introduction}

For some years we have been involved in the synthesis and study of an extensive library of bridging ligands characterised 15 by the schematic representation $1 .{ }^{1,2}$ These are comprised of a central arene core to which are appended a number $(n)$ of heterocyclic rings attached via spacer groups $(\mathrm{X})$. Variation of the arene core, the spacer group, the nature of the heterocycle and the number $n$ has led to an extensive array of compounds 20 that we have used for the construction of a diverse range of 1-, 2- and 3-D metallosupramolecular assemblies with various topological architectures. For example, several years ago we reported that reaction of silver(I) nitrate with 1,4-bis(2pyridyloxy)benzene, which has a benzene core, an ether 25 oxygen as spacer and $(n=2) 2$-substituted pyridines as the appended heterocycles, led to the dimetallocyclophane $\mathbf{2}$, the structure of which is stabilised by intimate internal $\pi-\pi$ stacking of the central benzene rings. ${ }^{3}$ The related 1,3disubstituted ligand (3) led to a topologically similar 30 assembly ${ }^{4}$ and several other disilver metallocyclophanes with similar $\pi-\pi$ stacking interactions have since been reported. ${ }^{5}$ In order to extend the distance between the two silver centres, we decided to replace the central benzene ring in $\mathbf{2}$ with a

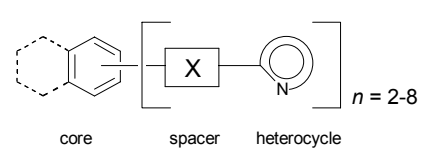

(1)

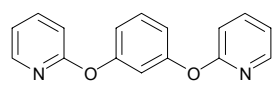

(3)

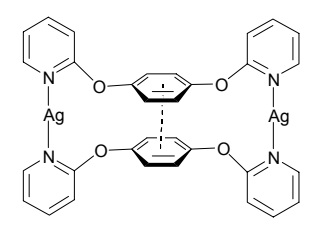

(2)

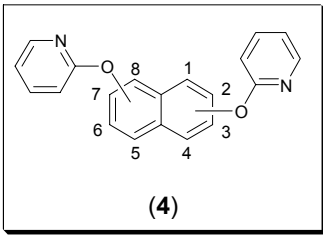

${ }^{a}$ Department of Chemistry, College of Science, University of Canterbury, Christchurch 8020, New Zealand. Fax:++64-3-3642110; Tel: ++64-33642432; E-mail: peter.steel@canterbury.ac.nz

$\dagger$ Electronic Supplementary Information (ESI) available: X-ray crystallographic data for compounds $\mathbf{5}, \mathbf{7 ,} 9$ and $\mathbf{1 0}$. See http://dx.doi.org/10.1039/b000000x/ naphthalene unit and recently reported the syntheses of the 35 isomeric bis(2-pyridyloxy)naphthalenes required for this purpose. ${ }^{6}$ We now report that reactions of these isomers with silver(I) nitrate leads to more complex behaviour, wherein the structure of the species produced shows a remarkable dependence on the specific substitution pattern in the 40 naphthalene core of the ligand.

\section{Results and Discussion}

Whereas disubstitution of a benzene ring allows only three ( $O$ , $m$ - and $p$-) isomeric possibilities, a naphthalene unit has ten possible disubstitution patterns. Of these, six have the two 45 substituents symmetrically related, whilst the other four isomers are unsymmetrical. In our experience symmetrical isomers are preferable for use as bridging synthons in metallosupramolecular chemistry, as they avoid the possibility of isomer formation in the self-assembly process. ${ }^{1}$ For this so reason, the complexes of the symmetrical isomers will be discussed first. All complexes were prepared by reaction of silver(I) nitrate with one equivalent of the ligand in methanol solution. Isolated yields were in the range $57-89 \%$.

\section{${ }_{55}$ Symmetrical isomers}

Of the six possible symmetrical bis(2-pyridyloxy)naphthalene isomers, the 1,8 -isomer proved synthetically inaccessible and the 1,4-isomer was peculiarly insoluble in all common ${ }_{60}$ solvents. $^{6}$ We have previously reported that the 2,7-isomer produces an unusual $\mathrm{M}_{2} \mathrm{~L}_{4}$ molecular box. ${ }^{7}$ We now report the results of reactions of the three other symmetrical isomers.

Reaction of the 2,6-isomer gave a product 5 in good yield that was shown by elemental analysis to have 1:1 metal:ligand 65 stoichiometry. This could correspond to either a discrete cyclic structure or a linear polymer. Crystals of this complex were not stable and decomposed, even in the mother liquor, within a few days. However, it was possible to perform a single-crystal X-ray structure determination on a freshly 70 prepared sample. While the crystals proved to be twinned, a data set corresponding to a monoclinic setting was abstracted from the larger pool of data and provided a clear solution and reasonably satisfactory refinement. 


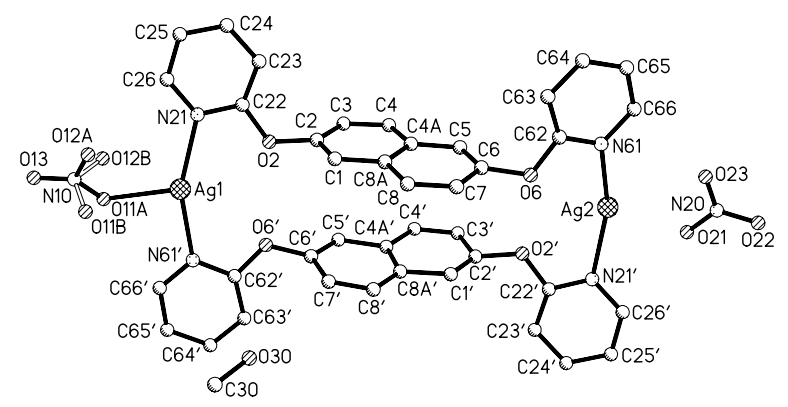

Fig. 1 Perspective view of the asymmetric unit of $\mathbf{5}$. Hydrogen atoms are omitted for clarity. Selected bond lengths $(\AA)$ and angles $\left({ }^{\circ}\right)$ : Ag1-N21 2.250(5), Ag1-N61' 2.230(6), Ag1-O11A 2.559(9), Ag2-N61 2.224(6), Ag2-N21' 2.238(6); N21-Ag1-N61' 156.1(2), N21-Ag1-O11A 111.8(3), N61'-Ag1-O11A 85.0(3), N61-Ag2-N21' 151.4(2).

The complex crystallises in the space group $\mathrm{P} 2{ }_{1} / \mathrm{c}$ and is a ${ }_{75} \mathrm{M}_{2} \mathrm{~L}_{2}$ dimetallomacrocycle. Two bridging ligands and two silver nitrates combine to form a [2+2] macrocycle, which, with a methanol solvate molecule, constitutes the asymmetric unit, Fig. 1. Each silver atom is coordinated to two pyridine nitrogens, and one silver atom is additionally coordinated to a 80 nitrate oxygen which has occupancy of 0.55 . This nitrate is disordered over two sites with the second site being considered non-coordinating and having an occupancy of 0.45. All four silver-pyridine bond lengths are similar and are within the expected range for such compounds. ${ }^{8}$ The deviation 85 from linearity of the $\mathrm{N}-\mathrm{Ag}-\mathrm{N}$ angles is in response to the presence of the nearby nitrate anions. ${ }^{9}$ The pyridine rings containing N21 and N61 are inclined to their connecting naphthalene at angles of $101.5(6)$ and $89.9(6)^{\circ}$, respectively, while the pyridines containing N21' and N61' are inclined to 90 their connecting naphthalene at angles of 106.8(6) and $102.2(6)^{\circ}$, respectively, thereby precluding the possibility of higher crystallographic symmetry.

A feature of the structure is the $\pi-\pi$ stacking of the naphthalene cores, which are nearly parallel, being inclined to ${ }_{95}$ each other at $1.5(6)^{\circ}$, and separated by $3.45(1) \AA$. The naphthalenes are slightly offset, so that two bonds of one naphthalene sit over the centroids of the rings of the other naphthalene unit. The silver-silver separation in the earlier complex (2) was $10.384(1) \AA{ }^{3}$ while in the present structure 100 the incorporation of a naphthalene spacer increases the separation to $12.578(1) \AA$. Thus, this ligand also leads to a $\mathrm{M}_{2} \mathrm{~L}_{2}$ dimetallomacrocycle stablised by internal $\pi-\pi$ stacking, suggesting that this is a general structural topology for such compounds. However this structure differs from that of $\mathbf{2}$ in 105 that there are additional weak intermolecular interactions that connect these dimeric units into chains. Specifically, weak Ag-Ag interactions [3.183(1) $\AA]$ and $\pi-\pi$ stacking [3.53(1) $\AA]$ between pyridine rings of adjacent molecules are observed. Similar interactions have been previously reported in related 110 assemblies. $^{10}$

Numerous unsuccessfully attempts were made to prepare a silver nitrate complex of the 2,3-isomer. The complex (6) was eventually obtained as a white microcrystalline solid by vapour diffusion of diethyl ether into a concentrated methanol 115 solution containing the ligand and silver nitrate. The complex was found, by elemental analysis, to have an intriguing $M_{3} L_{2}$ composition. The reaction was repeated using the appropriate stoichiometry and 6 was obtained in $57 \%$ yield. However all attempts to grow crystals suitable for X-ray structure 120 determination failed and the exact nature of this potentially interesting complex remains unknown.

Reaction of the 1,5-isomer furnished the silver complex (7) as a pale brown solid in $77 \%$ yield. Slow evaporation of an acetonitrile solution of $\mathbf{7}$ gave colourless crystals that analyse 125 as having a 1:1 metal:ligand ratio. Again this stoichiometry is consistent with a [2+2] macrocycle or with a metallopolymer and therefore an X-ray crystal structure determination was carried out.

This complex also crystallises in the centrosymmetric space 130 group $\mathrm{P} 2{ }_{1} / \mathrm{c}$ and is a one-dimensional zig-zag metallopolymer. The asymmetric unit contains two half-molecules of the bridging ligand, each of which lies on a centre of inversion, and one silver nitrate moiety. The asymmetric unit and connected atoms are labelled and shown as part of the 135 polymeric chain in Fig. 2.

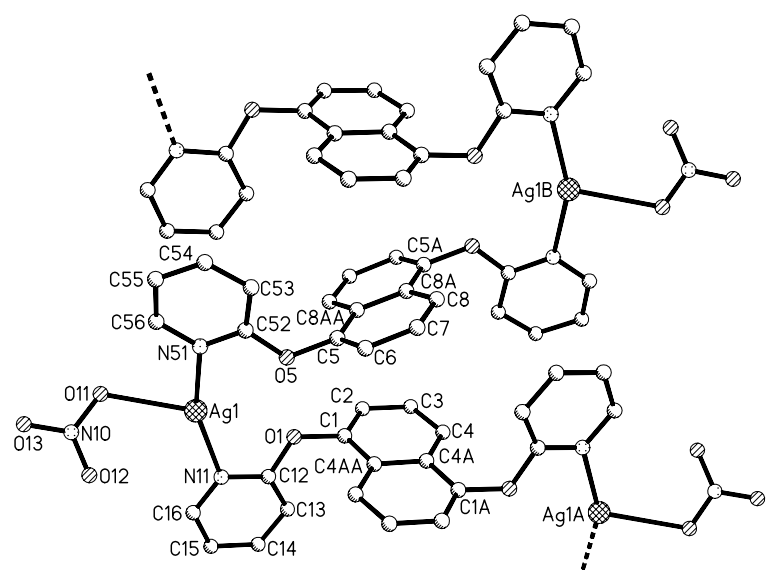

Fig. 2 Perspective view of the polymeric chain of 7, including the labelled asymmetric unit. Hydrogen atoms are omitted for clarity. Selected bond lengths $(\AA)$ and angles $\left({ }^{\circ}\right)$ : Ag1-N11 2.190(5), Ag1-N51 2.230(4), Ag1O11 2.555(4); N11-Ag1-N51 155.5(2), N11-Ag1-O11 116.0(2), N51Ag1-O11 86.9(2).

The silver atom is coordinated to two pyridine nitrogens and a monodentate nitrate ion. The silver-donor bond lengths are within the expected range for compounds of this type. ${ }^{8}$ The geometry at silver is best described as distorted T-shaped. 140 The polymer chain propagates along the crystallographic $a$ axis with silver-silver separations of 11.366(2) and 11.528(2) $\AA$ for two silvers bridged by ligands (Ag1 $\cdots \mathrm{Ag} 1 \mathrm{~A}$, $\mathrm{Ag} 1 \cdots \mathrm{Ag} 1 \mathrm{~B})$ and $8.930(2) \AA$ for two silvers along the edge of the polymer $(\mathrm{Ag} 1 \mathrm{~A} \cdots \mathrm{Ag} 1 \mathrm{~B})$, this being the $a$ cell dimension. ${ }_{145}$ Although the naphthalene units are not $\pi-\pi$ stacked [being inclined at an angle of $26.6(6)^{\circ}$ and separated by $\left.4.47(1) \AA\right]$, the pyridine rings are involved in such interactions. The first of these interactions is a weak intra-chain interaction with a pyridine-pyridine separation of 3.85(1) $\AA$. A much stronger 150 inter-chain interaction exists between two pyridine rings of adjacent chains related by a centre of inversion, so that they are necessarily parallel and have a separation of only 3.31(1) $\AA$. 
Thus the two isomeric (2,6- and 1,5-) symmetrical isomers 155 produce different supramolecular assemblies, a metallomacrocycle and a zig-zag coordination polymer, respectively. Silver coordination polymers have been the subject of much recent attention. ${ }^{11}$

\section{${ }_{160}$ Unsymmetrical isomers}

Of the four unsymmetrical bis(2-pyridyloxy)naphthalenes, we were unable to synthesise the 1,2 -isomer. ${ }^{6}$ The three other isomers all produced silver nitrate complexes in good yields.

165 The reaction of 1,3-bis(2-pyridyloxy)naphthalene with silver(I) nitrate provided a complex $\mathbf{8}$ that was shown by elemental analysis to have a 1:1 metal:ligand ratio, consistent with either a $\mathrm{M}_{2} \mathrm{~L}_{2}$ metallocycle or a linear coordination polymer. Unfortunately all crystals of this complex proved to 170 be both twinned and disordered. This is perhaps not surprising given that a metallocyclophane derived from an unsymmetrical ligand of this type can exist as four possible isomers, depending on whether the bridging ligands are arranged in a head-to-head (HH) or head-to-tail fashion (HT)

175 and whether the cofacial naphthalene units have a syn-or antiarrangement. These syn-HH, syn-HT, anti-HH and anti-HT isomers are shown below and have $\mathrm{C}_{\mathrm{s}}, \mathrm{C}_{2}, \mathrm{C}_{2}$ and $\mathrm{C}_{\mathrm{i}}$ symmetry, respectively.

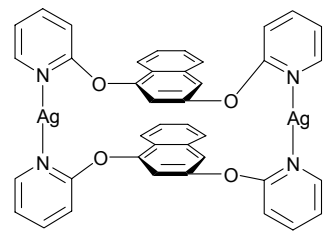

syn- $\mathrm{HH}$

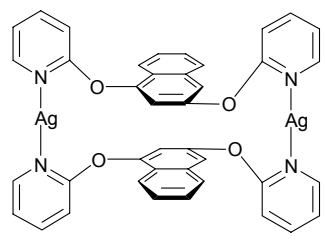

anti-HH

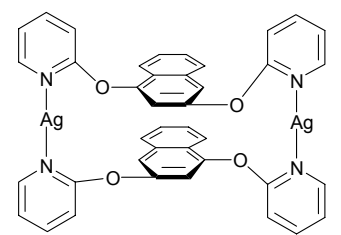

syn-HT

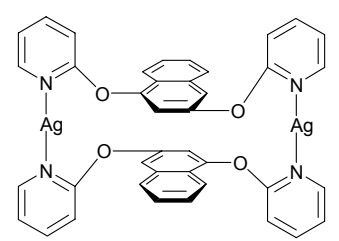

anti-HT
Despite the twinning and disorder, a structure solution was 180 obtained from a partial dataset but it did not refine to a level suitable for publication. Nevertheless, we were able to establish that the asymmetric unit contained two of the above dimetallocyclophanes and that one of these was the syn-HT isomer and the other appeared to be a disordered mixture of 185 the two syn-isomers. This suggests that the syn-isomers are preferred over the anti-isomers, as we previously found ${ }^{4}$ for the complex derived from ligand $\mathbf{3}$ which can also exist as syn- or anti-isomers. This is probably due to the existence of more extensive $\pi-\pi$ stacking within these isomers. The

190 presence of both HH and HT isomers reflects the very similar coordination environments of the two non-equivalent nitrogen donors in the ligand.

Reaction of 1,6-bis(2-pyridyloxy)naphthalene with silver(I) nitrate gave a complex (9) in high yield. Once again elemental 195 analysis revealed a 1:1 metal:ligand stoichiometry and the structure was unambiguously established by X-ray crystallography. This complex crystallises in the centrosymmetric triclinic space group $\mathrm{P}-1$ and is a onedimensional metallopolymer. Within the asymmetric unit 200 there are two bridging ligands, two silver nitrates, a coordinated water molecule and 1.5 methanol solvate molecules. The labelled asymmetric unit and the adjacent unit of the polymer are shown in Fig. 3 .

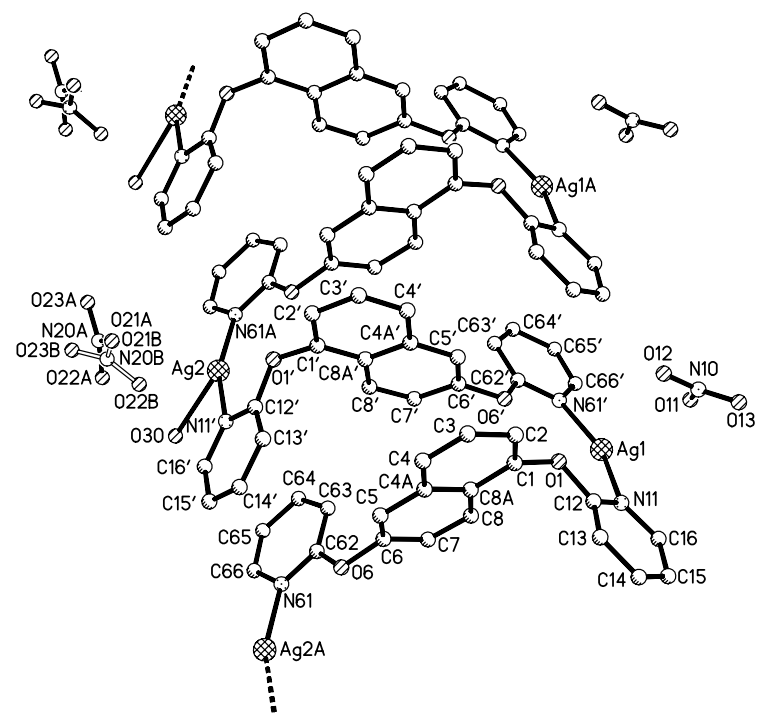

Fig. 3 Perspective view of the labelled asymmetric unit of 9 as part of the polymeric chain. Hydrogen atoms and solvate molecules are omitted for clarity. Selected bond lengths $(\AA)$ and angles $\left({ }^{\circ}\right)$ : Ag1-N11 2.190(9), Ag1-N61' 2.172(7), Ag2-N11' 2.184(9), Ag2-N61A 2.137(9), Ag2-O30 2.518(10); N11-Ag1-N61' 160.0(3), N11'-Ag2-N61A 158.7(3), N11'Ag1-O30 88.4(3), N61A-Ag2-O30 110.2(3).

Each silver is coordinated to two pyridine nitrogens, with 205 each of the pyridines being of a different nature. One pyridine is 1 -substituted on the naphthalene unit while the other is 6-substituted. This requires remarkable molecular recognition by the silver during the assembly process, which involves a faithful head-to-tail alignment of the ligands such 210 that the silver atom is able to distinguish the two pyridines, despite the fact that they differ only slightly in their structural environment. Ag2 is weakly coordinated to the water molecule and has distorted T-shaped geometry while Ag1 has a bent linear geometry. The silver-donor bond lengths are 215 again normal for this type of compound. ${ }^{8}$ The polymer chains propagate along the crystallographic $a$ axis by way of a translation. This results in the Ag1 $\cdots \mathrm{Ag} 1 \mathrm{~A}$ (and $\mathrm{Ag} 2 \cdots \mathrm{Ag} 2 \mathrm{~A}$ ) separation being 7.900(3) $\AA$ which is the $a$ unit cell dimension, while the Ag1 ‥Ag2 separation is $10.746(3) \AA$.

Once again $\pi-\pi$ stacking plays an important role within the structure, but does not involve the naphthalene units. Instead the pyridine rings are involved in both intra-chain and interchain stacking interactions. Within the chain all pyridine rings stack with pyridine rings from the next ligand in the chain to 225 which they are inclined at angles of $12.8(9)$ or $7.6(9){ }^{\circ}$ and separated by distances of 3.53(1) or 3.62(1) $\AA$.

The silver complex (10) of the 1,7-isomer was obtained, by diffusion of diethyl ether into the methanolic reaction mixture, as colourless crystals in $82 \%$ yield. It too showed a $1: 1$ 230 metal:ligand ratio and was fully characterised by X-ray 


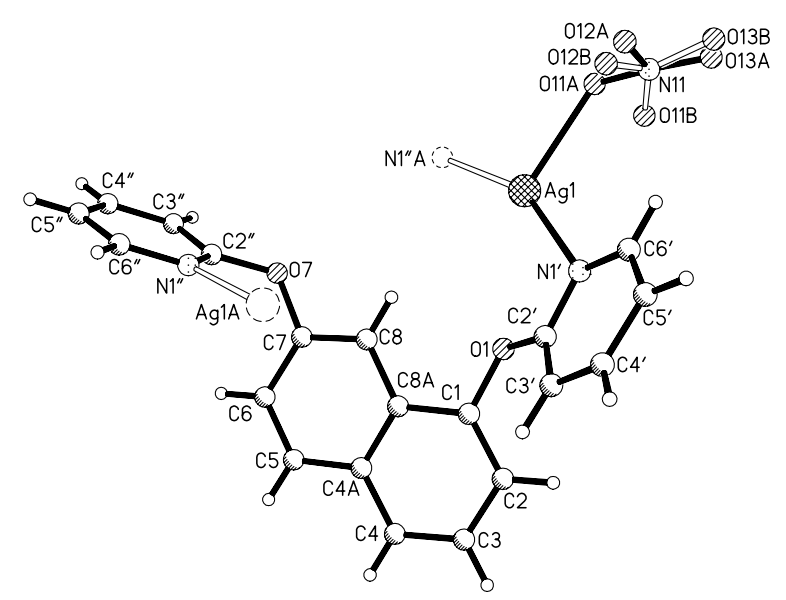

Fig. 4 Perspective view of the labelled asymmetric unit of 10. Selected bond lengths $(\AA)$ and angles $\left({ }^{\circ}\right)$ : Ag1-N1' 2.238(3), Ag1-N1"A 2.246(3), Ag1-O11A 2.360(9); N1'-Ag1-N1"A 154.4(1), N1'-Ag-O11A 108.9(3), N1"A-Ag1-O11A 96.7(3).

crystallography. It crystallises in the non-centrosymmetric orthorhombic space group $\mathrm{Pna} 2_{1}$ and is a one-dimensional single-stranded helicate. The asymmetric unit is shown in Fig. 4 and contains one bridging ligand and a silver nitrate 235 with the nitrate anion disordered over two orientations. The silver atom is coordinated to two different types of pyridine, which again requires the silver atoms to recognise these differences during the assembly process. The helical chain propagates along the crystallographic $c$ axis and the length of 240 the repeat unit of the chain is the length of the $c$ axis; therefore the silver-silver separation $(\mathrm{Ag} 1 \cdots \mathrm{Ag} 1 \mathrm{~A})$ is 5.464(1) $\AA$ (the $c$ cell dimension). Compared to the earlier structures, this much shorter distance spanned by the bridging ligand results from the compact conformation adopted by the ligand 245 itself. This is possible due to the presence of the 2-substituted pyridine rings and the flexibility provided by the ether oxygen linker. ${ }^{1}$ Such a twisted conformation is a necessary requirement for helicate formation. ${ }^{12}$ Although each helical chain is chiral, adjacent chains are related by a glide plane and 250 therefore have opposite chirality, as shown in Fig. 5. Surprsingly, there are no $\pi-\pi$ stacking interactions between any of the aromatic rings in this structure. A number of helical polymeric $\operatorname{Ag}(\mathrm{I})$ complexes have been reported in recent years. $^{11,13}$

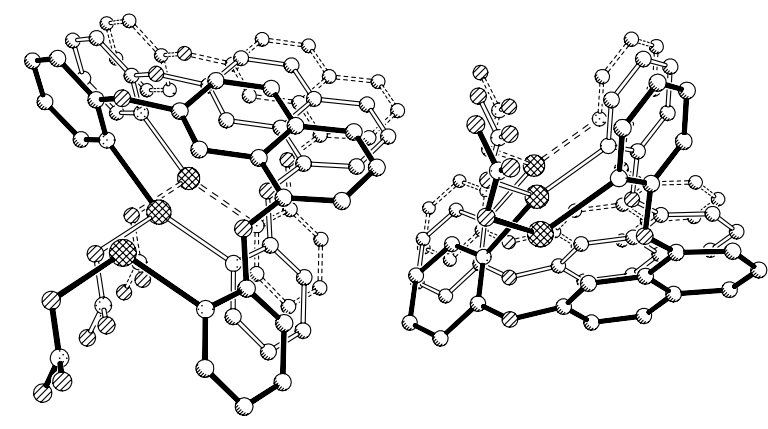

Fig. 5 View showing two helical chains of 10. The helicate on the left has chirality $M$, while that on the right has chirality $P$.

\section{${ }_{255}$ Conclusions}

Silver nitrate complexes of six isomeric ligands, differing only in the substitution pattern within the central naphthalene unit, have been shown to have a variety of supramolecular architectures, including dimetallocyclophanes, linear 260 coordination polymers and a single-stranded helicate. These results serve to highlight the subtle features that are involved in supramolecular isomerism and the difficulties associated with the understanding of self-assembly processes. ${ }^{14}$ The control of supramolecular self-assembly remains one of the 265 most challenging problems in chemistry.

\section{Experimental}

Melting points were determined using an Electrothermal melting point apparatus and are uncorrected. Elemental analyses were performed by the Chemistry Department, 270 University of Otago, Dunedin.

\section{Synthesis}

The isomeric bis(2-pyridyloxy)naphthalenes were prepared as 275 previously reported. ${ }^{6}$

2,6-Bis(2-pyridyloxy)naphthalene complex (5). Reaction of 2,6-bis(2-pyridyloxy)naphthalene (31 mg, $0.099 \mathrm{mmol}$ ) dissolved in hot methanol $(10 \mathrm{~mL})$ with silver nitrate $(17 \mathrm{mg}$, $2800.10 \mathrm{mmol})$ in hot methanol $(4 \mathrm{~mL})$ gave a colourless solution. This solution was taken to dryness in vacuo and the resulting pale brown solid was redissolved in the minimum volume of hot methanol and the resulting solution was filtered. Colourless crystals of $\mathbf{5}$, suitable for single crystal X285 ray structure determination, were obtained overnight $(38 \mathrm{mg}$, 74\%). Mp 209-211 ${ }^{\circ} \mathrm{C}$ (Found $\mathrm{C}, 49.72 ; \mathrm{H}, 2.68 ; \mathrm{N}, 8.77$. $\mathrm{C}_{20} \mathrm{H}_{14} \mathrm{~N}_{3} \mathrm{O}_{5} \mathrm{Ag}$ requires $\left.\mathrm{C}, 49.61 ; \mathrm{H}, 2.91 ; \mathrm{N}, 8.68\right)$.

2,3-Bis(2-pyridyloxy)naphthalene complex (6). Reaction 290 of 2,3-bis(2-pyridyloxy)naphthalene (30 $\mathrm{mg}, 0.095 \mathrm{mmol})$ dissolved in hot methanol $(10 \mathrm{~mL})$ with silver nitrate $(24 \mathrm{mg}$, $0.14 \mathrm{mmol})$ in hot methanol $(5 \mathrm{~mL})$ gave a colourless solution. The solvent was removed under reduced pressure to give a white residue. The residue was redissolved in the 295 minimum volume of hot methanol $(\sim 2 \mathrm{~mL})$, into which was diffused diethyl ether to give $\mathbf{6}$ as a white microcrystalline material (31mg, 57\%). Mp 127-129 ${ }^{\circ} \mathrm{C}$ (Found $\mathrm{C}, 42.63$; $\mathrm{H}$, 2.45; N, 8.45. $\mathrm{C}_{40} \mathrm{H}_{28} \mathrm{~N}_{7} \mathrm{O}_{13} \mathrm{Ag}_{3}$ requires $\mathrm{C}, 42.21 ; \mathrm{H}, 2.48 ; \mathrm{N}$, $8.61)$.

300

1,5-Bis(2-pyridyloxy)naphthalene complex (7). Reaction of 1,5-bis(2-pyridyloxy)naphthalene (60 mg, $0.19 \mathrm{mmol})$ dissolved in acetone $(15 \mathrm{~mL})$ with silver nitrate $(32 \mathrm{mg}, 0.19$ mmol) dissolved in water $(5 \mathrm{~mL})$ gave crude 6 as a pale brown 305 solid $(71 \mathrm{mg}, 77 \%)$. Slow evaporation of an acetonitrile solution of 7 gave crystals suitable for single crystal X-ray structure determination. Mp 246-248 ${ }^{\circ} \mathrm{C}$ (Found C, 49.68; $\mathrm{H}$, 2.89; N, 8.75. $\mathrm{C}_{20} \mathrm{H}_{14} \mathrm{~N}_{3} \mathrm{O}_{5} \mathrm{Ag}$ requires $\mathrm{C}, 49.61 ; \mathrm{H}, 2.91 ; \mathrm{N}$, $8.68)$. 
Table 1 Crystal data and X-ray experimental data for complexes 5, 7,9 and $\mathbf{1 0 .}$

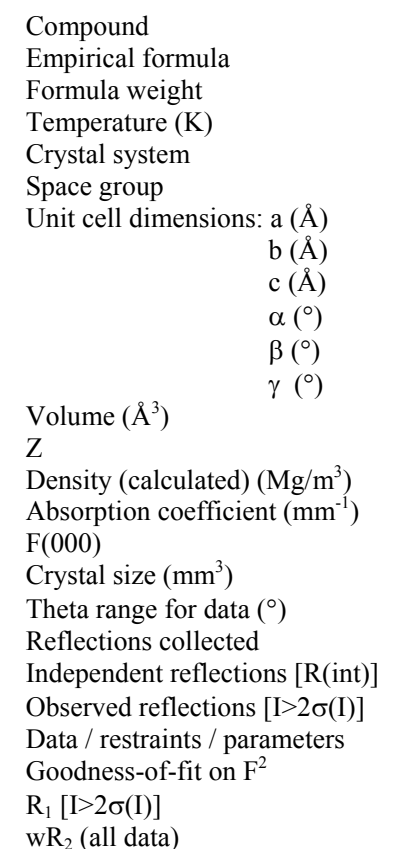

5

$\mathrm{C}_{41} \mathrm{H}_{32} \mathrm{Ag}_{2} \mathrm{~N}_{6} \mathrm{O}$ 1000.47

168(2)

Monoclinic

$\mathrm{P} 2{ }_{1} / \mathrm{c}$

10.902(2)

$20.356(5)$

$17.467(4)$

90

90.410(3)

90

$3876.0(15)$

4

1.714

1.082

2008

$0.65 \times 0.55 \times 0.25$

2.12 to 26.38

49057

7873 [0.0438]

5954

7873 / 0 / 562

1.049

0.0627

0.1347

\begin{tabular}{|c|c|}
\hline 7 & 9 \\
\hline $\mathrm{C}_{20} \mathrm{H}_{14} \mathrm{AgN}_{3} \mathrm{O}_{5}$ & $\mathrm{C}_{41.5} \mathrm{H}_{36} \mathrm{Ag}_{2} \mathrm{~N}_{6} \mathrm{O}_{12.5}$ \\
\hline 484.21 & 1034.51 \\
\hline $163(2)$ & $168(2)$ \\
\hline Monoclinic & Triclinic \\
\hline $\mathrm{P} 2{ }_{1} / \mathrm{c}$ & P-1 \\
\hline $8.930(2)$ & $7.900(3)$ \\
\hline $17.710(3)$ & $14.352(5)$ \\
\hline $11.2524(2)$ & $19.379(7)$ \\
\hline 90 & $73.447(5)$ \\
\hline $97.52(2)$ & $84.509(4)$ \\
\hline 90 & $78.025(4)$ \\
\hline $1806.8(6)$ & $2058.8(12)$ \\
\hline 4 & 2 \\
\hline 1.780 & 1.669 \\
\hline 1.156 & 1.024 \\
\hline 968 & 1042 \\
\hline $0.63 \times 0.11 \times 0.08$ & $0.82 \times 0.18 \times 0.10$ \\
\hline 2.30 to 25.00 & 2.09 to 25.05 \\
\hline 3998 & 24325 \\
\hline $3174[0.0363]$ & $7287[0.0620]$ \\
\hline 1888 & 4821 \\
\hline $3174 / 0 / 262$ & 7287 / 25 / 603 \\
\hline 0.828 & 1.095 \\
\hline 0.0413 & 0.0835 \\
\hline 0.0873 & 0.2074 \\
\hline
\end{tabular}

\section{0}

$\mathrm{C}_{20} \mathrm{H}_{14} \mathrm{AgN}_{3} \mathrm{O}_{5}$

484.21

148(2)

Orthorhombic

Pna 2

17.6095(4)

18.6243(4)

$5.4636(1)$

90

90

90

1791.87(6)

4

1.795

1.165

968

$0.80 \times 0.16 \times 0.15$

1.59 to 25.05

15685

3121 [0.0425]

2703

3121 / 33 / 290

1.072

0.0278

0.0696
1,3-Bis(2-pyridyloxy)naphthalene complex (8). Reaction of 1,3-bis(2-pyridyloxy)naphthalene (30 $\mathrm{mg}, 0.095 \mathrm{mmol}$ ) dissolved in hot methanol $(5 \mathrm{~mL})$ with silver nitrate $(32 \mathrm{mg}$, $0.095 \mathrm{mmol})$ in hot methanol $(5 \mathrm{~mL})$ gave a colourless 315 solution. The volume was reduced to $\sim 1 \mathrm{~mL}$ and vapour diffusion of diethyl ether into this solution furnished $\mathbf{8}$ as colourless crystals suitable for single crystal X-ray structure determination (31 mg, 67\%). Mp 134-136 ${ }^{\circ} \mathrm{C}$ (Found C, 49.37; $\mathrm{H}, 2.88 ; \mathrm{N}, 8.72$. $\mathrm{C}_{40} \mathrm{H}_{28} \mathrm{~N}_{6} \mathrm{O}_{10} \mathrm{Ag}_{2}$ requires $\mathrm{C}, 49.61 ; \mathrm{H}, 2.91$; $320 \mathrm{~N}, 8.68$ ).

1,6-Bis(2-pyridyloxy)naphthalene complex (9). Reaction of 1,6-bis(2-pyridyloxy)naphthalene $(60 \mathrm{mg}, 0.19 \mathrm{mmol})$ dissolved in hot methanol $(10 \mathrm{~mL})$ with silver nitrate $(32 \mathrm{mg}$, $3250.19 \mathrm{mmol})$ in hot methanol $(8 \mathrm{~mL})$ gave a colourless solution. This solution was concentrated under reduced pressure to approximately $3 \mathrm{~mL}$. Vapour diffusion of diethyl ether into this solution gave $\mathbf{9}$ as colourless crystals suitable for single crystal X-ray structure determination (82 $\mathrm{mg}, 89 \%$ ). ${ }_{330} \mathrm{Mp}$ 118-120 ${ }^{\circ} \mathrm{C}$ (Found C, 49.22; H, 3.00; N, 8.37. $\mathrm{C}_{20} \mathrm{H}_{14} \mathrm{~N}_{3} \mathrm{O}_{5} \mathrm{Ag}$ requires $\left.\mathrm{C}, 49.61 ; \mathrm{H}, 2.91 ; \mathrm{N}, 8.68\right)$.

1,7-Bis(2-pyridyloxy)naphthalene complex (10). Reaction of 1,7-bis(2-pyridyloxy)naphthalene (60 $\mathrm{mg}, 0.19 \mathrm{mmol})$ 335 dissolved in hot methanol $(5 \mathrm{~mL})$ with silver nitrate $(32 \mathrm{mg}$, $0.19 \mathrm{mmol})$ in hot methanol $(5 \mathrm{~mL})$ gave a colourless solution. The solvent was removed under reduced pressure to give an oily residue. The residue was redissolved in the minimum volume of hot methanol $(\sim 2 \mathrm{~mL})$. Upon cooling

340 this solution gave $\mathbf{1 0}$ as colourless crystals suitable for single crystal X-ray structure determination (76 mg, 82\%). Mp 187$188^{\circ} \mathrm{C}$ (Found $\mathrm{C}, 49.50 ; \mathrm{H}, 2.91 ; \mathrm{N}, 8.64 . \mathrm{C}_{20} \mathrm{H}_{14} \mathrm{~N}_{3} \mathrm{O}_{5} \mathrm{Ag}$ requires $\mathrm{C}, 49.61 ; \mathrm{H}, 2.91 ; \mathrm{N}, 8.68)$.

\section{${ }_{345}$ Crystal structure determination}

The crystal data, data collection and refinement parameters are given in Table 1. Measurements were made with a Bruker CCD area detector (or in the case of 7 a Siemens P4s four350 circle diffractometer) using graphite monochromatised Mo $\mathrm{K} \alpha$ $(\lambda=0.71073 \AA)$ radiation. The intensities were corrected for Lorentz and polarisation effects and for absorption. The structures were solved by direct methods using SHELXS, ${ }^{15}$ and refined on $F^{2}$ using all data by full-matrix least-squares 355 procedures using SHELXL-97. ${ }^{16}$ All non-hydrogen atoms were refined with anisotropic displacement parameters. Hydrogen atoms were included in calculated positions with isotropic displacement parameters 1.2 times the isotropic equivalent of their carrier carbon atoms. The functions 360 minimised were $\Sigma w\left(F_{\mathrm{o}}{ }^{2}-F_{\mathrm{c}}{ }^{2}\right)$, with $w=\left[\sigma^{2}\left(F_{\mathrm{o}}{ }^{2}\right)+\mathrm{a} P^{2}+\mathrm{b} P\right]^{-}$

${ }^{1}$, where $P=\left[\max \left(F_{\mathrm{o}}\right)^{2}+2 F_{\mathrm{c}}{ }^{2}\right] / 3$.

CCDC reference numbers 620549 - 620552. For crystallographic data in CIF or other electronic format see DOI: $10.1039 /$ b000000x.

365

\section{Acknowledgements}

We thank the Royal Society of New Zealand for funding through the Marsden Fund and a James Cook Research Fellowship.

\section{${ }_{370}$ Notes and references}

1 P. J. Steel, Acc. Chem. Res., 2005, 38, 243-250.

2 M. R. A. Al-Mandhary, P. J. Steel, Eur. J. Inorg. Chem., 2004, 329334 , and references therein.

3 C. M. Hartshorn, P. J. Steel, Inorg. Chem., 1996, 35, 6902-6903.

3754 C. M. Hartshorn, P. J. Steel, J. Chem. Soc., Dalton Trans., 1998, $3927-3934$. 
5 R.-F. Song, Y.-B. Xie, J.-R. Li, X.-H. Bu, Dalton Trans., 2003, 47424748; C. Janiak, Dalton, 2000, 3885-3896; S. Leininger, B. Olenyuk, P. J. Stang, Chem. Rev., 2000, 100, 853-907; C. M. Hartshorn, P. J. Steel, J. Chem. Soc., Dalton Trans., 1998, 3935-3940; M. Munakata, L. P. Wu, T. Kuroda-Sowa, Adv. Inorg. Chem., 1999, 46, 173-303.

6 B. J. O’Keefe, P. J. Steel, Molecules, 2006, 11, 684-692; B. J. O'Keefe, P. J. Steel, Organometallics, 2003, 22, 1281-1292.

7 B. J. O'Keefe, P. J. Steel, Inorg. Chem. Commun., 1998, 1, 147-149.

3858 M. Hedrich, H. Hartl, Acta Cryst., Sect. C, 1983, 39, 1649-1652; L. M. Engelhardt, C. Pakawatchai, A. H. White, P. C. Healy, J. Chem. Soc., Dalton Trans., 1985, 117-123; G. Smith, A. N. Reddy, K. A. Byriel, C. H. Kennard, Polyhedron, 1994, 13, 2425-2430, and references therein.

3909 M. A. M. Abu-Youssef, V. Langer, L. Öhrström, Dalton Trans., 2006, 2542-2550.

10 K. Singh, J. R. Long, P. Stavropoulos, J. Am. Chem. Soc., 1997, 119, 2942-2943; G. Baum, E. C. Constable, D. Fenske, C. E. Housecroft, T. Kulke, Chem. Commun., 1998, 2659-2660; P. L. Caradoc-Davies,

395 L. R. Hanton, W. Henderson, J. Chem. Soc., Dalton Trans., 2001, 2749-2755; D. A. McMorran, P. J. Steel, Supramol. Chem., 2002, 14, 79-85; J. Moussa, K. Boubekeur, H. Amouri, Eur. J. Inorg. Chem., 2005, 3808-3810; Q. L. Chu, D. C. Swenson, L. R. MacGillivray, Angew. Chem., Int. Ed., 2005, 44, 3569-3572; L. Dobrzanska, H. G.

400 Raubenheimer, L. J. Barbour, Chem. Commun., 2005, 5050-5052; A. A. Mohamed, L. M. Perez, J. P. Fackler, Inorg. Chim. Acta, 2005, 258, 1657-1662; H. P. Zhang, Y. B. Wang, X. C. Huang, Y. Y. Lin, X. M. Chen, Chem.-Eur. J., 2005, 11, 552-561; L. R. Hanton, A. G. Young, Cryst. Growth Des., 2006, 6, 833-835.

40511 M. Munakata, L. P. Wu, T. Kuroda-Sowa, Adv. Inorg. Chem., 1999, 46, 173-303; A. N. Khlobystov, A. J. Blake, N. R. Champness, D. A. Lemenovskii, A. G. Majouga, N. V. Zyk, M. Schröder, Coord. Chem. Rev., 2001, 222, 155-192; S.-L. Zheng, M.-L. Tong, X.-M. Chen, Coord. Chem. Rev., 2003, 246, 185-202; C.-L. Chen, B.-S. Kang, C.-

410 Y. Su, Aust. J. Chem., 2006, 59, 3-18; C. M. Fitchett, P. J. Steel, Aust. J. Chem., 2006, 59, 19-21; D. B. Cordes, L. R. Hanton, M. D. Spicer, Inorg. Chem., 2006, 45, 7651-7664.

12 C. Piguet, G. Bernardinelli, G. Hopfgartner, Chem. Rev., 1997, 97, 2005-2062; M. Albrecht, Chem. Rev., 2001, 101, 3457-3497; M. J. Hannon, L. J. Childs, Supramol. Chem., 2004, 16, 7-22.

13 See, for example: E. Psillakis, J. C. Jeffery, J. A. McCleverty, M. D. Ward, J. Chem. Soc., Dalton Trans., 1997, 1645-1651; B. Wu, W.-J. Zhang, S.-Y. Yu, X.-T. Wu, J. Chem. Soc., Dalton Trans., 1997, 1795-1796; M.-L. Tong, X.-M. Chen, B.-H. Ye, Inorg. Chem., 1998,

420 37, 5278-5281; L. Carlucci, G. Ciani, D. M. Proserpio, A. Sironi, Inorg. Chem., 1998, 37, 5941-5943; H.-P. Wu, C. Janiak, G. Rheinwald, H. Lang, J. Chem. Soc., Dalton Trans., 1999, 183-190; P. L. Caradoc-Davies, L. R. Hanton, Chem. Commun., 2001, 10981099.

42514 B. Moulton, M. J. Zaworotko, Chem. Rev., 2001, 101, 1629-1658; J.P. Zhang Y.-Y. Lin, X.-C. Huang, X.-M. Chen, Chem. Commun., 2005, 1258-1260; K. M. Fromm, J. L. Sagué Doimeadios, A. Y. Robin, Chem. Commun., 2005, 4548-4550.

15 G. M. Sheldrick, Acta Cryst., 1990, A46, 467-473.

43016 G. M. Sheldrick, SHELXL-97: Programs for Crystal Structure Analysis, University of Göttingen, Germany, 1997. 


\section{Graphical Abstract}

Rings, Chains and Helicates: Dependence of Metallosupramolecular Topology on Positional Substitution within Silver(I) Complexes of Six Isomeric Bis(2-pyridyloxy)naphthalenes

Brendan J. O’Keefe and Peter J. Steel

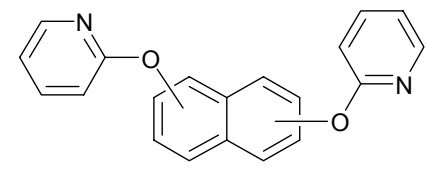

6 isomers
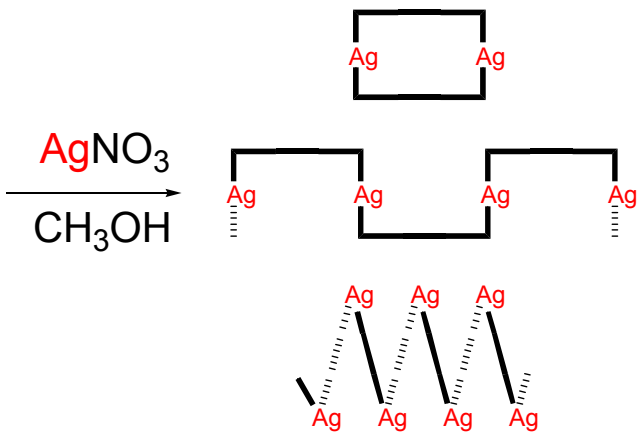

Silver(I) nitrate complexes of six isomeric bis(2-pyridyloxy)naphthalenes, differing only in the substitution pattern within the central naphthalene unit, have been shown to have an unexpected assortment of supramolecular architectures, including dimetallocyclophanes, linear coordination polymers and a single-stranded helicate. 